ARTICLE

Received 3 Sep 2013 | Accepted 20 Dec 2013 | Published 27 Jan $2014 \quad$ DOI: 10.1038/ncomms4170

\title{
Polystyrene sulphonic acid resins with enhanced acid strength via macromolecular self-assembly within confined nanospace
}

\author{
Xiaomin Zhang ${ }^{1,2}$, Yaopeng Zhao ${ }^{1}$, Shutao $\mathrm{Xu}^{3}$, Yan Yang ${ }^{1}$, Jia Liuํ․ Yingxu Wei ${ }^{3} \&$ Qihua Yang ${ }^{1}$
}

\begin{abstract}
Tightening environmental legislation is driving the chemical industries to develop efficient solid acid catalysts to replace conventional mineral acids. Polystyrene sulphonic acid resins, as some of the most important solid acid catalysts, have been widely studied. However, the influence of the morphology on their acid strength-closely related to the catalytic activity-has seldom been reported. Herein, we demonstrate that the acid strength of polystyrene sulphonic acid resins can be adjusted through their reversible morphology transformation from aggregated to swelling state, mainly driven by the formation and breakage of hydrogen bond interactions among adjacent sulphonic acid groups within the confined nanospace of hollow silica nanospheres. The hybrid solid acid catalyst demonstrates high activity and selectivity in a series of important acid-catalysed reactions. This may offer an efficient strategy to fabricate hybrid solid acid catalysts for green chemical processes.
\end{abstract}

\footnotetext{
${ }^{1}$ State Key Laboratory of Catalysis, Dalian Institute of Chemical Physics, Chinese Academy of Sciences, 457 Zhongshan Road, Dalian 116023, China.

${ }^{2}$ University of Chinese Academy of Sciences, Beijing 100049, China. ${ }^{3}$ National Engineering Laboratory for Methanol to Olefins, Dalian National Laboratory for Clean Energy, Dalian Institute of Chemical Physics, Chinese Academy of Sciences, 457 Zhongshan Road, Dalian 116023, China. Correspondence and requests for materials should be addressed to Q.Y. (email: yangqh@dicp.ac.cn).
} 
$\mathrm{D}$ riven by environmental consideration and safety concerns, the replacement of hazardous and corrosive mineral acids by solid acids is one of the important tasks for green and sustainable production of chemicals ${ }^{1-8}$. Polystyrene sulphonic acid resins $\left(\mathrm{PS}_{-} \mathrm{SO}_{3} \mathrm{H}\right.$ ) are among the very important solid acids in industry and have been widely used in acidcatalysed reactions such as esterification, olefin hydration, etherification and alkylation of phenols ${ }^{9-13}$. They generally exhibit high concentration of acid sites but poor thermal stability and very low surface area. A straightforward strategy for improving thermal stability and for increasing surface area is to prepare polymer/silica hybrid composites, which could take advantages of high surface area, high thermal stability and antiswelling properties of silica materials via either physically mixing or covalently bonding method ${ }^{14-17}$. Although polymer/ silica hybrid composites exhibit increased thermal stability, higher exposure degree of acid sites and larger BET (BrunauerEmmett-Teller) surface area in comparison with their polymer

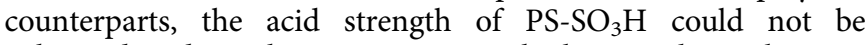
enhanced and on the contrary it might become lower because of the reduced acid density by this approach ${ }^{18}$. It has been reported that the increment in acid density and spatial proximity may increase the cooperative effect among acid sites, consequently enhancing the acid strength of PS- $\mathrm{SO}_{3} \mathrm{H}^{19,20}$.

As for inorganic solid acids, the acid strength could be adjusted by varying several factors, for example, crystallinity, topology structure and morphology, in addition to the chemical compositions ${ }^{21-27}$. For example, microporous zeolites with crystalline nature exhibit stronger acid strength than mesoporous Al-MCM41 with amorphous nature, even though they are both composed of aluminosilicates ${ }^{21}$. Recently, it has been reported that Brönsted acid strength of the titanate nanotubes is higher than that of the titanate nanosheets, which is attributed to the lattice distortion derived from scrolling of the lamellar titanate nanosheet ${ }^{24}$. As for the polymer-based solid acids, the principal strategy to enhance acid strength is to add electron-withdrawing groups on the sulphonated phenyl groups ${ }^{27}$. Great challenge still remains for improving the acid strength via factors beyond chemical compositions, probably due to the lack of methods for morphology, structure and crystalline controls of polymers.

Macromolecular self-assembly that involves thermodynamically controlled association of molecules into aggregates has been widely used for the fabrication of polymers with well-defined structures ${ }^{28-33}$. Generally, the self-assembly is performed in bulk solution system via interactions among specific functional groups, for example, H-bond interactions, hydrophobic interactions, electrostatic interactions and $\pi-\pi$ stacking. The macromolecular self-assembly in a confined nanospace has seldom been investigated and may be distinctively different from that in bulk solution system due to the confinement effect in nanospace, relatively high local concentration of substrates, restricted movement freedom of substrates and so on.

Herein, we report the fabrication of a hybrid solid acid with a double-shell nanostructure (DSNs) via the self-assembly of

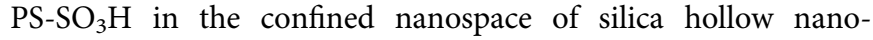
spheres (HNs). The acid strength of $\mathrm{PS}_{-} \mathrm{SO}_{3} \mathrm{H}$ can be reversibly enhanced and decreased by the expansion and aggregation of PS- $\mathrm{SO}_{3} \mathrm{H}$ within the confined nanospace, which is confirmed by ${ }^{31} \mathrm{P}$ MAS NMR, ammonia adsorption calorimetry and TEM (transmission electron microscopy) characterizations. In a series of important acid-catalysed reactions, such as esterification of fatty acid, Friedel-Crafts alkylation of toluene and cumene hydroperoxide (CHP) cleavage, the solid catalyst exhibits much higher activity than Amberlyst-15, and in some cases even higher than liquid acid, $\mathrm{H}_{2} \mathrm{SO}_{4}$, under similar reaction conditions.

\section{Results}

Morphology and nanostructure. The general procedure for the synthesis of hybrid solid acid is outlined in Fig. 1a. Initially, PS template spheres with a particle size of $\sim 200 \mathrm{~nm}$ were prepared

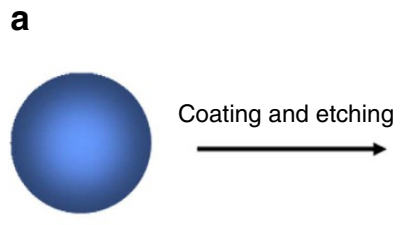

PS

b

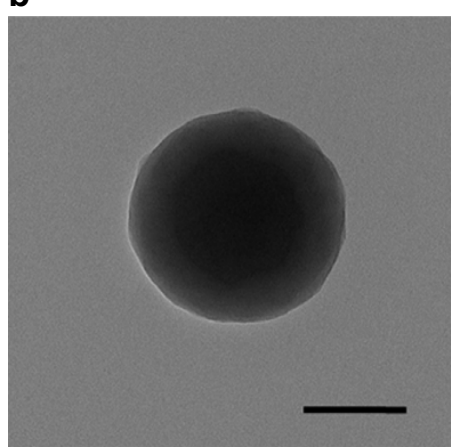

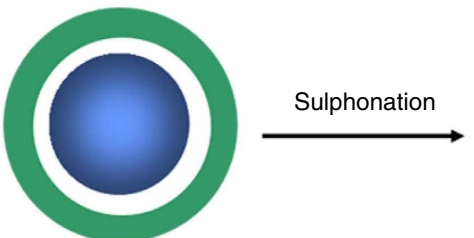

PS@mesosilicas YSNs

C

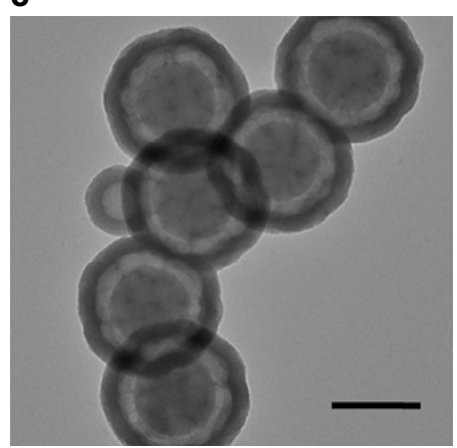

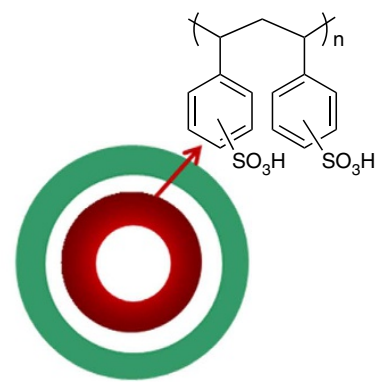

PS-SO ${ }_{3} \mathrm{H} @$ mesosilicas DSNs

d

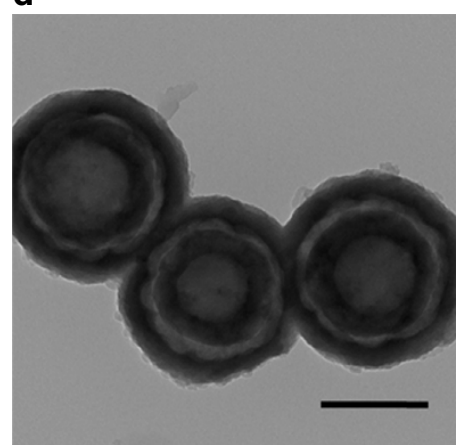

Figure 1 | Synthesis and characterization of PS-SO $\mathbf{H}$ @mesosilicas DSNs. (a) Schematic illustration showing the general procedure for the synthesis of PS-SO3H@mesosilicas DSNs. (b) TEM image of PS template. Scale bar, 100 nm. (c) TEM image of PS@mesosilicas YSNs. Scale bar, 200 nm.

(d) TEM image of PS-SO $\mathrm{SO}_{3} \mathrm{H}$ mesosilicas DSNs. Scale bar, $200 \mathrm{~nm}$. 
by emulsion polymerization in water system (Fig. 1b and Supplementary Fig. 1a). Then PS@mesosilicas with yolk-shell nanostructures (YSNs) were synthesized according to a modified organosilane-assisted etching method that we reported previously using 1,2-bis-(trimethoxysilyl)ethane (BTME) as the organosilane precursor $^{34,35}$. The TEM image shows that the core diameter and shell thickness of PS@mesosilicas YSNs are $\sim 200$ and $\sim 40 \mathrm{~nm}$, respectively, and the void between core and shell is $\sim 40 \mathrm{~nm}$ (Fig. 1c). After surfactant extraction, PS@mesosilicas YSNs were sulphonated with $\mathrm{ClSO}_{3} \mathrm{H}$ in $\mathrm{CH}_{2} \mathrm{Cl}_{2}$ for the formation of PS-SO ${ }_{3} \mathrm{H} @ m e s o s i l i c a s$ DSNs. The SEM image shows that PS-SO $\mathrm{S}_{3} \mathrm{H}$ mesosilicas DSNs are mono-dispersed nanospheres with a uniform particle size of $\sim 340 \mathrm{~nm}$, similar to YSNs before sulphonation, and the broken particles clearly show the spherein-sphere morphology (Supplementary Fig. 1b). The TEM image clearly verifies that this sample has double-shell hollow nanostructure with inner-shell thickness of $\sim 60 \mathrm{~nm}$ and outershell thickness of $\sim 40 \mathrm{~nm}$, and the void space between the inner shell and the outer shell is of $\sim 40 \mathrm{~nm}$ (Fig. 1d). The highresolution-TEM element line images of $\mathrm{PS}-\mathrm{SO}_{3} \mathrm{H} @ m e s o s i l i c a s$ DSNs clearly show that $\mathrm{Si}$ and $\mathrm{S}$ are mainly distributed in the outer shell and inner shell, respectively (Fig. 2). For further identification of the composition of the outer and inner shell, PS$\mathrm{SO}_{3} \mathrm{H} @ m e s o s i l i c a s$ DSNs were treated in $\mathrm{HF}$ and calcined under air atmosphere to remove silica and $\mathrm{PS}-\mathrm{SO}_{3} \mathrm{H}$, respectively. According to the TEM images, both the HF-treated and the calcined samples are HNs with the same particle sizes as the outer
( $340 \mathrm{~nm})$ and inner ( 200 nm) HNs of PS-SO 3 H@mesosilicas DSNs (Fig. 3a,b). The above results demonstrate that the outer and inner shell of PS-SO 3 H@mesosilicas DSNs are composed of silica and $\mathrm{PS}-\mathrm{SO}_{3} \mathrm{H}$, respectively.

Compositions and textural properties. The appearance of the vibration peaks assigned to $-\mathrm{CH}_{2} \mathrm{CH}_{2}$ at $2,934-2,844 \mathrm{~cm}^{-1}$ in the FTIR (Fourier transform infrared) spectra of PS@mesosilicas YSNs and PS-SO ${ }_{3} \mathrm{H} @$ mesosilicas DSNs confirms the successful wrapping of the ethane-silicas around the PS cores (Fig. 3c). The peaks at $1,450-1,630 \mathrm{~cm}^{-1}$ and $3,000-3,100 \mathrm{~cm}^{-1}$ are assigned to unsaturated $\mathrm{C}-\mathrm{C}$ and $\mathrm{C}-\mathrm{H}$ stretching vibration of phenyl groups. Two new peaks at 1,178 and $1,377 \mathrm{~cm}^{-1}$ attributed to sulphonic acid groups were observed in the FTIR spectrum of PS-SO $\mathrm{H}_{3} \mathrm{H} @ m e s o s i l i c a s$ DSNs. Compared with that of PS@meso-

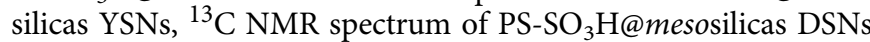
clearly shows the signal at around 142 p.p.m., which could be assigned to the aromatic carbon coordinated with $\mathrm{SO}_{3} \mathrm{H}$ groups, confirming the successful sulphonation (Supplementary Fig. 2).

The ${ }^{29}$ Si MAS NMR spectrum of PS-SO 3 H@mesosilicas DSNs displays two sets of resonance signals in the range of -35 to -85 p.p.m. and -80 to -120 p.p.m., which are respectively attributed to $\mathrm{T}$ and $\mathrm{Q}$ silicon species, with a $\mathrm{T} /(\mathrm{T}+\mathrm{Q})$ of 0.81 calculated by the integration of the peak area. This reveals the coexistence of ethane-silicas and silicas in the outer shell (Supplementary Fig. 3). The above characterizations indicate that a

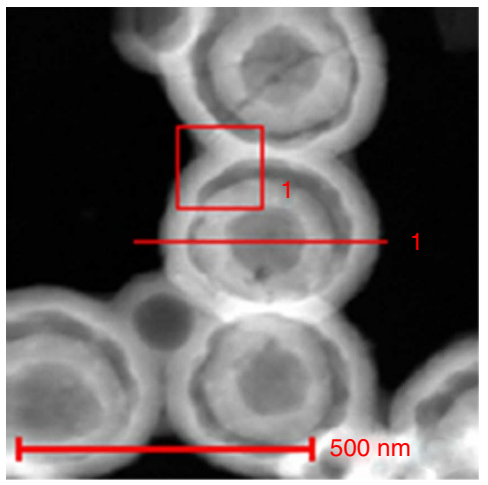

b

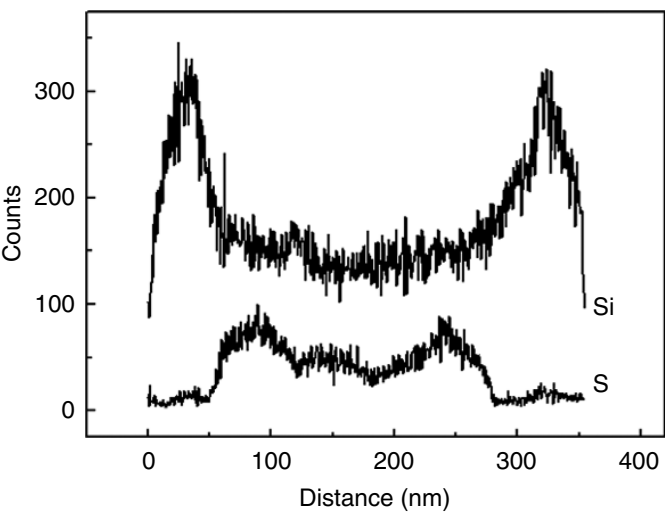

Figure 2 | Investigation of the PS-SO $\mathbf{S}_{3} \mathbf{H}$ location. (a) High-resolution-TEM image of PS-SO 3 H@mesosilicas DSNs. (b) Energy dispersive X-ray spectrometer (EDX) analysis along the line shown in (a) of PS- $\mathrm{SO}_{3} \mathrm{H} @$ mesosilicas DSNs.

a

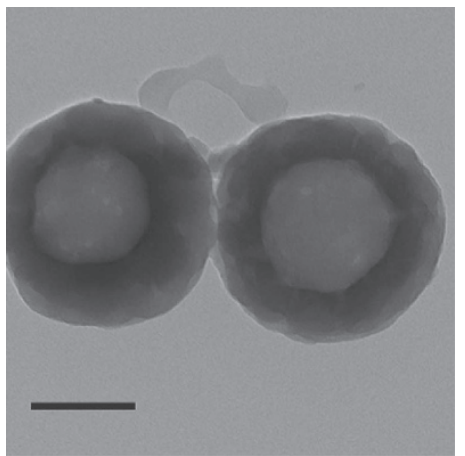

b

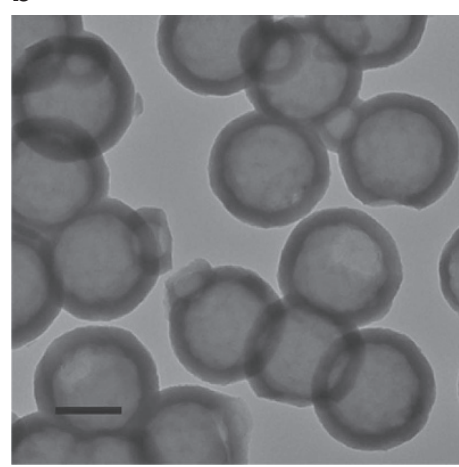

C

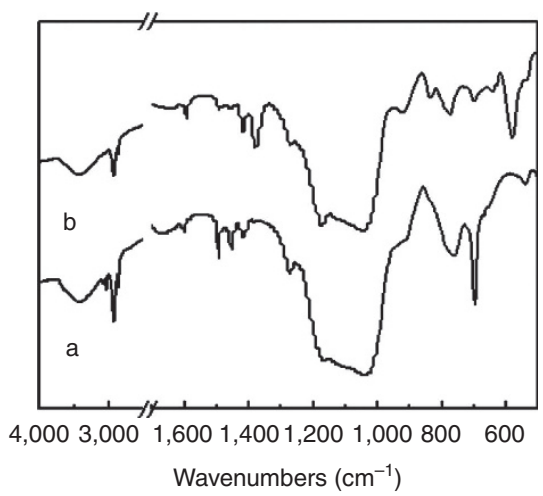

Figure 3 | Composition characterizations. (a) TEM image of PS- $\mathrm{SO}_{3} \mathrm{H} @$ mesosilicas DSNs after treament with HF. Scale bar, $100 \mathrm{~nm}$. (b) TEM image of PS-SO ${ }_{3} \mathrm{H} @$ mesosilicas DSNs after calcinations. Scale bar, 200 nm. (c) FTIR spectra of (a)PS@mesosilicas YSNs and (b) PS-SO $\mathrm{H}_{3} @ m e s o s i l i c a s$ DSNs. 
PS-SO $\mathrm{S}_{3} \mathrm{H} @ m e s o s i l i c a s$ DSNs are hybrid materials composed of PS- $\mathrm{SO}_{3} \mathrm{H}$, ethane-silicas and silicas.

The nitrogen adsorption-desorption isotherms of PS- $\mathrm{SO}_{3} \mathrm{H} @-$ mesosilicas DSNs display typical IV isotherm pattern with a sharp capillary condensation step and H4-type hysteresis loop starting from the relative pressure $\mathrm{P} / \mathrm{P}_{0}$ at 0.50 (Supplementary Fig. 4). This indicates the presence of mesopores in the outer shell, according to IUPAC classification (pore diameter of $2.1 \mathrm{~nm}$, similar to YSNs before sulphonation). The existence of the mesopores in the outer shell will benefit the free diffusion of guest molecules throughout the nanospheres. It should be mentioned that the $\mathrm{H} 4$ hysteresis in the $\mathrm{N}_{2}$ sorption isotherm of PS- $\mathrm{SO}_{3} \mathrm{H} @ m e s o s i l i c a s$ DSNs is probably from the hollow interiors of the DSNs ${ }^{34,36}$. PS-SO 3 H@mesosilicas DSNs have higher BET surface area $\left(412 \mathrm{~m}^{2} \mathrm{~g}^{-1}\right)$ and larger pore volume $\left(0.42 \mathrm{~cm}^{3} \mathrm{~g}^{-1}\right)$ than Amberlyst-15 (Supplementary Table 1).

Morphology changes with sulphonation time. The above results show that the morphology transformation from YSNs to DSNs takes place during the sulphonation process. For clarifying this interesting transformation mechanism, the samples were taken out at desired time intervals during the sulphonation process and characterized by the TEM technique (Fig. 4). At the initial $10 \mathrm{~min}$, only HNs could be observed with similar particle size but thicker shell comparing with PS@mesosilicas YSNs (75 versus $40 \mathrm{~nm}$ ), and this HNs' morphology was maintained in the first $2 \mathrm{~h}$. This is probably due to the adherence of dissolved PS to the inner surface of mesosilica HNs. Further extending the sulphonation time to $3 \mathrm{~h}$, the inner shell started to appear, and the transformation from
HNs to DSNs completed in $4 \mathrm{~h}$. It should be noted that once the inner HNs were completely generated, the outer-shell thickness changed back to $40 \mathrm{~nm}$, similar to that of the initial PS@mesosilicas YSNs. No further changes in morphology could be observed beyond $4 \mathrm{~h}$. The sulphur content increases from 2.1 to $2.4 \mathrm{mmol} \mathrm{g}^{-1}$ as the sulphonation time increases from 1 to $3 \mathrm{~h}$ (Fig. 5a). After that, the sulphur content tends to be constant, suggesting that the sulphonation reaction nearly completes within $3 \mathrm{~h}$. The acidic exchange capacity of the samples with sulphonation time $\leq 2 \mathrm{~h}$ is nearly identical to the sulphur content, however, it sharply decreases to $1.0 \mathrm{mmolg}^{-1}$ and levels off after $4 \mathrm{~h}$ (Fig. 5a). It is worthy to note that the volume of $\mathrm{PS}-\mathrm{SO}_{3} \mathrm{H}$ decreased from $8.37 \times 10^{-21}$ to $4.61 \times 10^{-21} \mathrm{~m}^{3}$ with sulphonation time increasing from 1 to $12 \mathrm{~h}$ based on TEM images, showing the aggregation of $\mathrm{PS}-\mathrm{SO}_{3} \mathrm{H}$ during the sulphonation process, which cause the percentage of inaccessible sulphonic acid groups to increase from 0.8 to $62.7 \%$ (Fig. $5 \mathrm{a}$ ). The above results show that the aggregation of $\mathrm{PS}_{-} \mathrm{SO}_{3} \mathrm{H}$ derived by the macromolecular self-assembly within the nanospace of silica $\mathrm{HNs}$ during the sulphonation process mainly contributes to the formation of inner HNs.

PS-SO $\mathrm{S}_{3} \mathrm{H} @ m e s o s i l i c a s$ DSNs are very stable and could maintain the DSN in various nonpolar or polar solvents such as methanol, THF, dioxane, water and pentane (Supplementary Fig. 5). However, in $N, N$-dimethylformamide (DMF), the morphology of PS-SO $\mathrm{S}_{3} \mathrm{H} @ m e s o s i l i c a s$ DSNs changed from DSN to hollow nanostructures (Supplementary Fig. 6). Interestingly, the HNs could be reversibly transformed back to the DSNs by treating with $\mathrm{ClSO}_{3} \mathrm{H}$. The reversible transformation process could be repeated for several times by alternative $\mathrm{DMF}$ and $\mathrm{ClSO}_{3} \mathrm{H}$ a

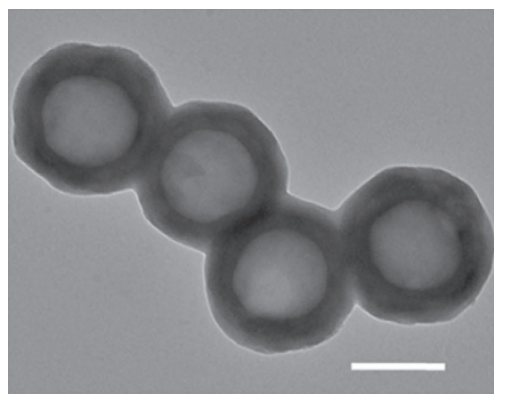

b

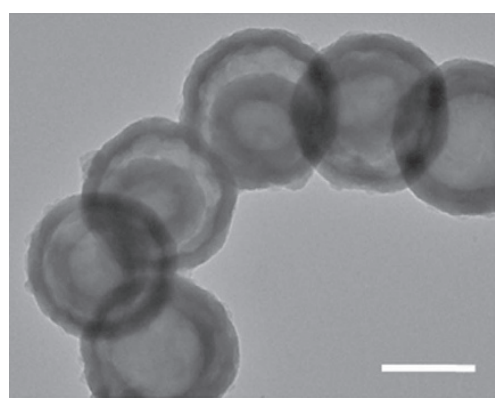

C

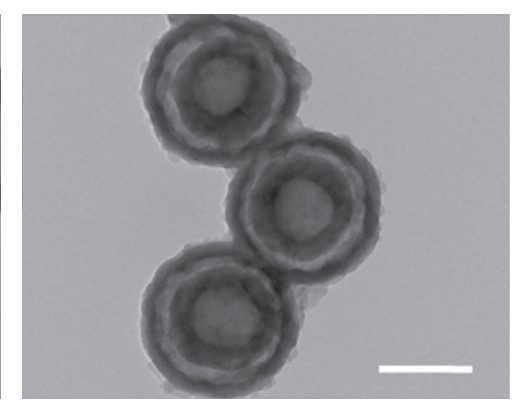

Figure 4 | Nanostructure evolution with different sulphonation time. (a) TEM images of the samples with sulphonation time of 10 min. Scale bar, $200 \mathrm{~nm}$. (b) TEM images of the samples with sulphonation time of $3 \mathrm{~h}$. Scale bar, $200 \mathrm{~nm}$. (c) TEM images of the samples with sulphonation time of $4 \mathrm{~h}$. Scale bar, $200 \mathrm{~nm}$.

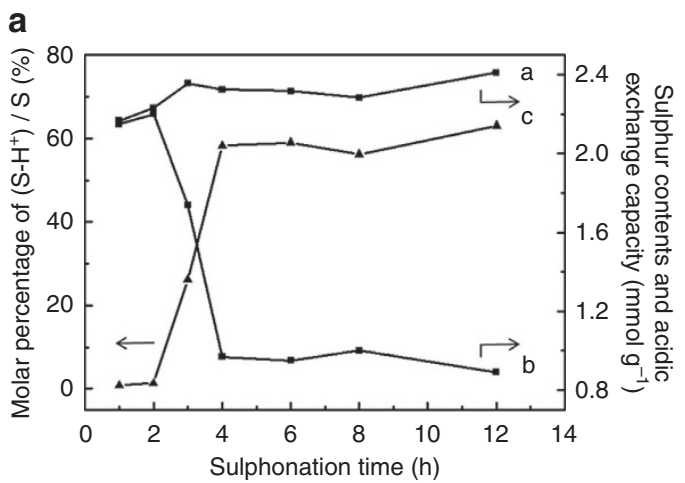

b

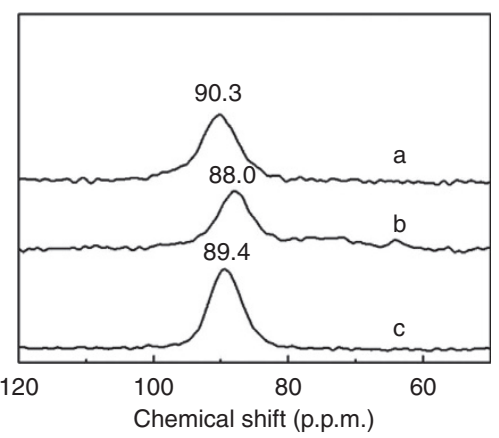

Figure 5 | Acidity and acid strength characterizations. (a) The sulphur contents (a), acidic exchange capacity (b) and the molar percentage of sulphur to acidic exchange capacity (c) of the samples with different sulphonation time. (b) ${ }^{31} \mathrm{P}$ MAS NMR spectra of PS-SO ${ }_{3} \mathrm{H} @ m e s o s i l i c a s ~ D S N s$ before (a) and after (b) DMF treatment and Amberlyst-15 (c). 
treatment (Supplementary Fig. 6). It was found that not only DMF but also pyridine can induce the transformation of HNs to DSNs (Supplementary Fig. 5). In addition to $\mathrm{ClSO}_{3} \mathrm{H}$, trifluoroacetic acid and $p$-toluene sulphonic acid could also induce the reversible transformation back to the DSNs (Supplementary Fig. 6). It seems that the above transformations are related with $\mathrm{H}$-bond interactions.

$\mathrm{H}$-bond interactions. For investigation of $\mathrm{H}$-bond interactions in PS-SO ${ }_{3} \mathrm{H} @ m e s o s i l i c a s$ DSNs, ${ }^{1} \mathrm{H}$ MAS NMR technique ${ }^{37-39}$, a useful and direct method for characterizing $\mathrm{H}$-bond interactions in both liquid and solid catalysts, was used. The ${ }^{1} \mathrm{H}$ MAS NMR spectra of PS-SO $\mathrm{S}_{3} \mathrm{H}$ mesosilicas DSNs and DMF-treated PS$\mathrm{SO}_{3} \mathrm{H} @$ mesosilicas DSNs display signals at 1.2, 2.7 and 7.4 p.p.m. originated from the protons of $-\mathrm{CH}-\mathrm{CH}$ - (ethylene group), $\mathrm{Si}-\mathrm{OH}$ (hydroxyl group) and $-\mathrm{PhH}$ (phenylene group), respectively (Supplementary Fig. 7). The signals at 13.5 p.p.m. should be derived from the protons of $\mathrm{SO}_{3} \mathrm{H}$ groups. However, the proton signal of $\mathrm{SO}_{3} \mathrm{H}$ group cannot be observed in the ${ }^{1} \mathrm{H}$ NMR spectrum of PS-SO ${ }_{3} \mathrm{H} @ m e s o s i l i c a s$ DSNs. After DMF treatment, the chemical shift at 13.5 p.p.m. assigned to the proton of sulphonic group ${ }^{19}$ was observed. Generally, the higher chemical shift suggests stronger $\mathrm{H}$-bond interactions among adjacent $\mathrm{SO}_{3} \mathrm{H}$ groups. Therefore, the absence of proton signals of $\mathrm{SO}_{3} \mathrm{H}$ for PS-SO $\mathrm{S}_{3} \mathrm{H} @ m e s o s i l i c a s$ DSNs may possibly be due to strong $\mathrm{H}$-bond interactions as a result of the aggregation of PS during the sulphonation process. This suggests that strong $\mathrm{H}$-bond interactions exist in $\mathrm{PS}-\mathrm{SO}_{3} \mathrm{H} @ m e s o s i l i c a s$ DSNs, and DMF treatment could suppress the H-bond interactions.

\section{Discussion}

On the basis of the above results, the formation of DSN during the sulphonation process may involve the dissolution of PS cores and the self-assembly of sulphonated PS driven by $\mathrm{H}$-bond interactions within the confined nanospace of silica HNs. During the sulphonation process, the PS swells and readily dissolves in $\mathrm{CH}_{2} \mathrm{Cl}_{2}$. However, the dissolved species could not escape out of the silica shell. Along with the sulphonation degree of PS increasing, the $\mathrm{H}$-bond interactions among adjacent $\mathrm{SO}_{3} \mathrm{H}$ groups are strengthened and subsequently trigger the self-assembly of $\mathrm{PS}-\mathrm{SO}_{3} \mathrm{H}$ within the nanospace of silica $\mathrm{HNs}$. In a control experiment, the sulphonation of PS in $\mathrm{CH}_{2} \mathrm{Cl}_{2}$ solution results in no solid products. Thus, the self-assembly of $\mathrm{PS}-\mathrm{SO}_{3} \mathrm{H}$ to form aggregated HNs strongly depends on the confined nanospace, which may restrict the free movement of swelled $\mathrm{PS}-\mathrm{SO}_{3} \mathrm{H}$ and enhance $\mathrm{H}$-bond interactions owing to the high local concentration of $\mathrm{PS}-\mathrm{SO}_{3} \mathrm{H}$.
The treatment of PS-SO 3 H@mesosilicas DSNs in aprotic polar solvents such as DMF and pyridine could destroy $\mathrm{H}$-bond interactions between sulphonic acid groups. The expansion of PS- $\mathrm{SO}_{3} \mathrm{H}$ occurs due to the swelling effect in $\mathrm{CH}_{2} \mathrm{Cl}_{2}$, which causes the formation of HNs. The further treatment of HNs with acids will help to restore the $\mathrm{H}$-bond interactions among sulphonic acid groups. Thus, the aggregation of $\mathrm{PS}-\mathrm{SO}_{3} \mathrm{H}$ results in the transformation of HNs back to DSNs. The above results suggest that $\mathrm{H}$-bond interactions play an important role in the morphology transformation of $\mathrm{PS}-\mathrm{SO}_{3} \mathrm{H}$.

The TG curves of $\mathrm{PS}_{-} \mathrm{SO}_{3} \mathrm{H}$ HNs (obtained by HF treatment of PS-SO ${ }_{3} \mathrm{H} @ m e s o s i l i c a s$ DSNs), PS-SO 3 H@mesosilicas DSNs and DMF-treated PS-SO ${ }_{3} \mathrm{H} @ m e s o s i l i c a s$ DSNs exhibit three consecutive weight loss steps in the range of $30-600^{\circ} \mathrm{C}$ (Supplementary Fig. 8), which is due to the loss of the physically adsorbed water, decomposition of sulphonic acids and destruction of polymer framework, respectively (the decomposition of ethane-silica in the shell of PS-SO 3 H@mesosilicas DSNs takes place at temperature above $400^{\circ} \mathrm{C}$ (ref. 40)). The decomposition temperature of sulphonic acids of PS-SO $\mathrm{S}_{3} \mathrm{H} @ m e s o s i l i c a s \mathrm{DSN}$ is $47^{\circ} \mathrm{C}$ higher than that of $\mathrm{PS}-\mathrm{SO}_{3} \mathrm{H}$ HNs, probably due to the protective effect of the shell. After treatment with DMF, the decomposition of sulphonic acids starts at lower temperature than that of the fresh PS-SO ${ }_{3} \mathrm{H} @ m e s o s i l i c a s$ DSNs (264 versus $294^{\circ} \mathrm{C}$ ). This suggests that $\mathrm{H}$-bond interactions could enhance the thermal stability of sulphonic acids.

The previous reports have shown that $\mathrm{H}$-bond interactions could influence the acid strength of solid acids ${ }^{19,41}$. Therefore the

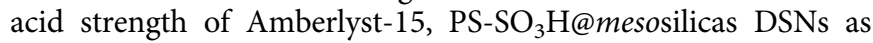
well as DMF-treated PS-SO $\mathrm{S}_{3} \mathrm{H} @ m e s o s i l i c a s$ DSNs was investigated using TEPO (triethylphosphine oxide) as a probe molecule in combination with ${ }^{31} \mathrm{P}$ MAS NMR technique (Fig. 5b). The ${ }^{31} \mathrm{P}$ chemical shift of TEPO chemisorbed on the acid site is sensitive to acid strength, and stronger acid strength will usually lead to larger ${ }^{31} \mathrm{P}$ chemical shift of $\mathrm{TEPO}^{42-44}$. The ${ }^{31} \mathrm{P} \mathrm{NMR}$ spectrum of Amberlyst-15 exhibits a signal at 89.4 p.p.m. that can be assigned to TEPO adsorbed on $\mathrm{SO}_{3} \mathrm{H}$ acid sites. The signal at 90.3 p.p.m. was observed in the ${ }^{31} \mathrm{P}$ NMR spectrum of PS- $\mathrm{SO}_{3} \mathrm{H} @ m e s o s i l i c a s$ DSNs. The downshift of the signal indicates that PS-SO ${ }_{3} \mathrm{H} @ m e s o s i l i c a s$ DSNs have stronger Brönsted acid strength than Amberlyst-15. However, the corresponding

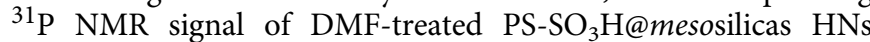
shows an upshift to 88.0 p.p.m., suggesting the decrease in acid strength. In combination with ${ }^{1} \mathrm{H}$ NMR results, the enhancement and decrease in the acid strength are probably related with $\mathrm{H}$-bond interactions. On the basis of the fact that an increase in the proximity of acid moieties will increase the acid strength due to the site cooperation effect by the formation of $\mathrm{H}$-bond

Table 1 | The acid strength and acid concentrations ${ }^{\star}$.

\begin{tabular}{|c|c|c|c|c|}
\hline Samples & $\begin{array}{c}\text { Acid exchange } \\
\text { capacity }\left(\mathrm{mmol} \mathrm{g}^{-1}\right)^{\dagger}\end{array}$ & $\begin{array}{c}\text { Total } \mathrm{NH}_{3} \text { adsorbed } \\
\left(\mathrm{mmol} \mathrm{g}^{-1}\right)^{\ddagger}\end{array}$ & $\begin{array}{c}\mathrm{NH}_{3} / \mathrm{H}^{+} \\
\left(\mathrm{mmol} \mathrm{mmol}^{-1}\right)^{\S}\end{array}$ & 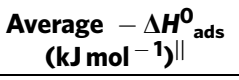 \\
\hline Amberlyst- 15 & 4.7 & 4.6 & 0.97 & 116 \\
\hline Nafion NR50 & 0.9 & 0.85 & 0.94 & 161 \\
\hline PS-SO3H@mesosilicas HNs & 1.7 & 1.1 & 0.65 & 125 \\
\hline PS-SO $\mathrm{H} @$ mesosilicas DSNs & 0.9 & 1.2 & 1.33 & 130 \\
\hline DMF-treated PS-SO $3 \mathrm{H} @ m e s o s i l i c a s ~ D S N s$ & 1.4 & 0.9 & 0.64 & 117 \\
\hline \multicolumn{5}{|c|}{ 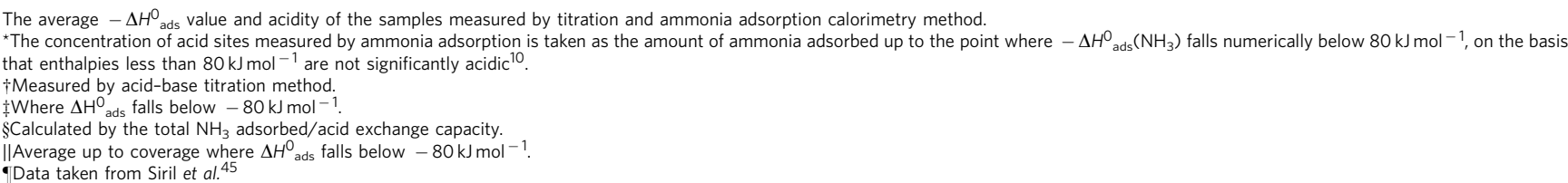 } \\
\hline
\end{tabular}


interactions between adjacent acid pairs ${ }^{22}$, it could be deduced that the enhanced acid strength could be attributed to strong $\mathrm{H}$-bond interactions, which can increase the cooperation effect by drawing $\mathrm{SO}_{3} \mathrm{H}$ groups closer.

The acid strength of the samples was also measured using ammonia adsorption calorimetry method (Table 1 and Supplementary Fig. 9). The concentration of acid sites measured by ammonia adsorption was similar to that measured using titration method for Amberlyst-15 and Nafion NR50. However, the ammonia adsorption method affords much lower acid sites than titration method for PS-SO $\mathrm{S}_{3} \mathrm{H}$ @mesosilicas HNs and DMFtreated PS- $\mathrm{SO}_{3} \mathrm{H} @ m e s o s i l i c a s$ DSNs. The above two samples both have hollow nanostructure. Some of the surface acid sites could form H-bond with the surface hydroxyl group of the organosilica shell and thus could not react with ammonia. The higher acid sites measured by ammonia adsorption method than those by titration method for PS-SO ${ }_{3} \mathrm{H} @ m e s o s i l i c a s$ DSNs is probably due to the $\mathrm{H}$-bond breakage effect of ammonia, which decreases the aggregation degree of $\mathrm{PS}-\mathrm{SO}_{3} \mathrm{H}$. An average value for $\Delta \mathrm{H}^{0}{ }_{\text {ads }}\left(\mathrm{NH}_{3}\right)$ was calculated and used to measure the acid strength of different samples (Table 1). $\Delta \mathrm{H}^{0}$ ads $\left(\mathrm{NH}_{3}\right)$ value of PS-SO ${ }_{3} \mathrm{H} @ m e s o s i l i c a s$ DSNs was about $130 \mathrm{~kJ} \mathrm{~mol}^{-1}$, which is lower than Nafion NR50 (ref. 45) but higher than Amberlyst-15. In comparison with $\mathrm{PS}-\mathrm{SO}_{3} \mathrm{H} @ m e s o s i l i c a s \mathrm{HNs}, \mathrm{PS}-\mathrm{SO}_{3} \mathrm{H} @$ mesosilicas DSNs afford higher $\Delta \mathrm{H}^{0}$ ads $\left(\mathrm{NH}_{3}\right)$ value, showing a remarkable enhancement in the acid strength by the formation of double-shell hollow nanostructure. After the DMF treatment, the obvious decrease in $\Delta \mathrm{H}^{0}$ ads $\left(\mathrm{NH}_{3}\right)$ suggests that the acid strength became weaker probably because of the suppressing of $\mathrm{H}$-bond interactions. The above results suggest that the acid strength of $\mathrm{PS}-\mathrm{SO}_{3} \mathrm{H}$ could be tuned by the morphology transformation within the confined nanospace of silica HNs. This provides a

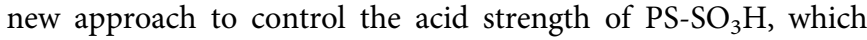
is commonly achieved by varying the chemical compositions and the acid loading.

The catalytic performance of PS-SO 3 H@mesosilicas DSNs was tested in several important acid-catalysed liquid-phase reactions, such as esterification of fatty acid, Friedel-Crafts alkylation of toluene and CHP (cumene hydroperoxide) cleavage (Fig. 6), and compared with those of Nafion NR50, Amberlyst-15 and $\mathrm{H}_{2} \mathrm{SO}_{4}$ (Table 2). The esterification of fatty acids with alcohol to produce esters represents an important pretreatment step in the production of biodiesel from high free fatty acid feedstocks. In the esterification of lauric acid with ethanol, all the acid catalysts show catalytic activity with ethyl laurate as the only product. $\mathrm{H}_{2} \mathrm{SO}_{4}$ gives a yield of $71.7 \%$ with turnover frequency (TOF) of $31.9 \mathrm{~h}^{-1}$ and Amberlyst- 15 affords a yield of $40.2 \%$ with TOF of $2.4 \mathrm{~h}^{-1}$. The low activity of Amberlyst-15 is probably due to the low exposing degree of the active sites to substrates (the BET surface area of Amberlyst-15 is only $45 \mathrm{~m}^{2} \mathrm{~g}^{-1}$ ). Under similar reaction conditions, PS-SO $\mathrm{SO}_{3} \mathrm{H} @ m e s o s i l i c a s$ DSNs reach a yield of $89.7 \%$ with TOF of $28.6 \mathrm{~h}^{-1}$. The higher yield of ethyl laurate on PS-SO ${ }_{3} \mathrm{H} @ m e s o s i l i c a s$ DSNs than on $\mathrm{H}_{2} \mathrm{SO}_{4}(89.7 \%$ versus $71.7 \%$ ) suggests that the unique DSN including hydrophobic $\mathrm{CH}_{2}-\mathrm{CH}_{2}$ - in the outer shell may prevent to some extent the water (formed during the esterification reaction) poisoning the acid sites. PS- $\mathrm{SO}_{3} \mathrm{H} @ m e s o s i l i c a s$ DSNs show much higher activity than PS- $\mathrm{SO}_{3} \mathrm{H}$ HNs, PS-SO $\mathrm{S}_{3} \mathrm{H}$ @mesosilicas HNs (obtained with sulphonation time of $3 \mathrm{~h}$ ) and DMF-treated PS-SO $\mathrm{S}_{3} \mathrm{H} @ m e s o$ silicas DSNs, showing that the external mesoporous organosilica shells and high acid strength ${ }^{45}$ benefit for improving the catalytic activity. The organosilica shell may help to stabilize the hollow structure of $\mathrm{PS}-\mathrm{SO}_{3} \mathrm{H}$ during the catalytic process. It should be mentioned that the sulphonated silica HNs exhibit only $4.9 \%$ conversion of lauric acid, showing that almost no sulphonic acid group could be incorporated in the shell during the sulphonation process.

The catalytic performance of different samples was also tested in Friedel-Crafts alkylation of toluene by benzyl alcohol, an important industry process to produce diphenyl compounds that are essential intermediates for pharmaceutical and fine chemical production ${ }^{46-48}$. All acid catalysts could catalyse this reaction with methyl diphenylmethanes as desired product and dibenzyl ether as side product (Supplementary Fig. 10). At an S/C of 57.5, $\mathrm{H}_{2} \mathrm{SO}_{4}$ shows a very low activity (4.9\% conversion with $50.1 \%$ selectivity to methyl diphenylmethanes). Only at high catalyst concentration (an S/C of 5), $\mathrm{H}_{2} \mathrm{SO}_{4}$ could afford $96.2 \%$ conversion with $78.8 \%$ selectivity to methyl diphenylmethanes. This suggests that high concentration of liquid acid is necessary for achieving desired activity. At an S/C of 57.5, PS-SO 3 H@mesosilicas DSNs that give 99.1\% conversion with $72.8 \%$ selectivity to methyl diphenylmethanes are much more active and selective than $\mathrm{H}_{2} \mathrm{SO}_{4}$ and Amberlyst-15. The fact that PS-SO ${ }_{3} \mathrm{H} @ m e s o s i l i c a s$ DSNs are less selective than Nafion NR50 but more selective than PS-SO $\mathrm{S}_{3} \mathrm{H} @$ mesosilicas HNs and DMFtreated PS-SO $\mathrm{S}_{3} \mathrm{H} @ m e s o s i l i c a s$ DSNs suggests that higher acid strength could result in higher selectivity. The low activity and selectivity of PS- $\mathrm{SO}_{3} \mathrm{H}$ HNs once again confirm the importance of the organosilica shell for obtaining high activity and selectivity.

In acid-catalysed cleavage of CHP into phenol and acetone, PS-SO ${ }_{3} \mathrm{H} @ m e s o s i l i c a s$ DSNs afford 99.5\% conversion with 99.8\% selectivity to phenol, which was much higher than $\mathrm{PS}^{-} \mathrm{SO}_{3} \mathrm{H} \mathrm{HNs}$, DMF-treated PS-SO $\mathrm{S}_{3} \mathrm{H}$ mesosilicas DSNs and Amberlyst-15. Considering dangerous explosive problem, the catalytic behaviour of $\mathrm{H}_{2} \mathrm{SO}_{4}$ was not tested. The above results suggest that the high activity and selectivity of $\mathrm{PS}-\mathrm{SO}_{3} \mathrm{H} @ m e s o s i l i c a s$ DSNs are probably attributed to their strong acid strength, high local concentration of active sites and unique DSN.

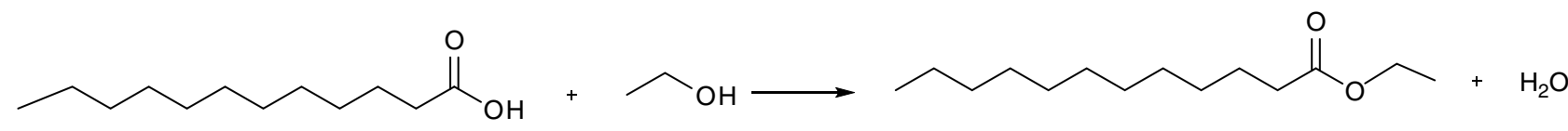

b
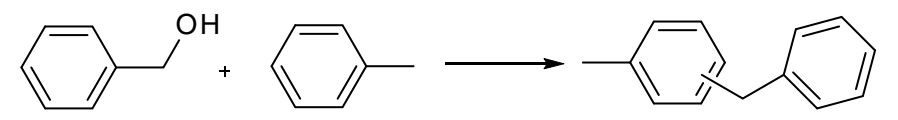

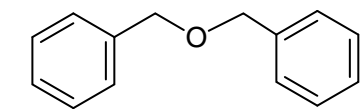

$+\mathrm{H}_{2} \mathrm{O}$
C

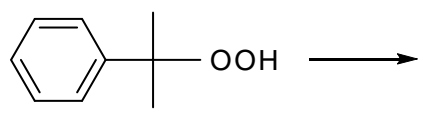

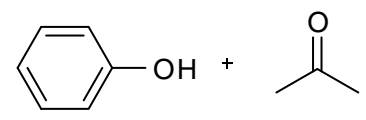

Figure 6 | Acid-catalysed liquid-phase reactions. (a) Esterification of fatty acid. (b) Friedel-Crafts alkylation of toluene. (c) Cumene hydroperoxide cleavage. 
Table 2 | Catalytic activity and selectivity.

\begin{tabular}{|c|c|c|c|c|c|c|c|c|}
\hline \multirow[t]{2}{*}{ Catalysts } & \multicolumn{2}{|c|}{ Esterification ${ }^{\star}$} & \multicolumn{3}{|c|}{ Friedel-Crafts alkylation ${ }^{\dagger}$} & \multicolumn{3}{|c|}{ CHP cleavage } \\
\hline & TOF $\left(h^{-1}\right)^{\S}$ & Conv. (\%) & TOF $\left(h^{-1}\right)^{\S}$ & Conv. (\%) & Sel. (\%)" & TOF $\left(h^{-1}\right)^{\S}$ & Conv. (\%) & Sel. (\%) \\
\hline $\mathrm{H}_{2} \mathrm{SO}_{4}$ & 31.9 & 71.7 & - & 4.9 & 50.1 & - & - & - \\
\hline Amberlyst-15 & 2.4 & 40.2 & 9.3 & 44.0 & 63.6 & 189.4 & 33.3 & 68.6 \\
\hline $\mathrm{PS}-\mathrm{SO}_{3} \mathrm{H} \mathrm{HNs}$ & 6.5 & 25.9 & 14.8 & 69.2 & 60.5 & 62.6 & 9.8 & 69.4 \\
\hline PS-SO ${ }_{3} \mathrm{H} @$ mesosilicas HNs & 11 & 75.7 & 20.4 & 99.6 & 67.5 & 627.4 & 98.1 & 99.0 \\
\hline 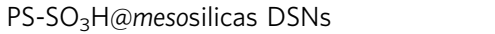 & 28.6 & 89.7 & 27.9 & 99.1 & 72.7 & 611.5 & 99.5 & 99.8 \\
\hline
\end{tabular}

The catalytic performance of different types of acid catalysts in esterification, Friedel-Crafts alkylation and CHP cleavage reactions (see Fig. 6).

*The esterification reaction was performed at $80^{\circ} \mathrm{C}$ for $6 \mathrm{~h}$ under the conditions of $0.04 \mathrm{mmol}$ of acid sites, $2 \mathrm{mmol}$ of lauric acid and $10 \mathrm{mmol}$ ethanol. The catalytic activities in esterification reaction were evaluated by lauric acid conversion.

†The Friedel-Crafts alkylation was performed at $80^{\circ} \mathrm{C}$ for $7 \mathrm{~h}$ under the conditions of $0.04 \mathrm{mmol}$ of acid sites, $2.3 \mathrm{mmol}$ of benzyl alcohol and $10 \mathrm{ml}$ toluene. The catalytic activities in Friedel-Crafts alkylation were evaluated by benzyl alcohol conversion.

$\ddagger$ The CHP cleavage reaction was performed at $50^{\circ} \mathrm{C}$ for $1 \mathrm{~h}$ under the conditions of $8.7 \times 10^{-3} \mathrm{mmol}$ of acid sites and $5.2 \mathrm{mmol}$ of $\mathrm{CHP}$. The catalytic activities in CHP cleavage reaction were evaluated by CHP conversion.

$\$$ For the calculation of TOFs, $\mathrm{H}^{+}$measured by acid-base titration method were used as active sites. The TOF was defined as mmol substrate converted per acid site per hour with conversion less than $30 \%$.

\|The selectivity to methyl diphenylmethanes.

- The selectivity to phenol.

\#The sample was obtained with sulphonation time of $3 \mathrm{~h}$.

The recycle stability of $\mathrm{PS}-\mathrm{SO}_{3} \mathrm{H} @ m e s o s i l i c a s$ DSNs was investigated using esterification of lauric acid with ethanol as the model reaction (Supplementary Fig. 11). The solid catalyst could be easily recovered by centrifugation. After being washed and dried, the recovered catalyst was directly used for the next reaction cycle. The fresh solid catalyst gave $93.3 \%$ yield of ethyl laurate within $6 \mathrm{~h}$. In the second run, the yield slightly dropped to $87.9 \%$ under the same reaction condition. After the second cycle the yield becomes quite steady in the following cycles (for example, $86.6 \%$ yield for the eighth cycle), suggesting that $\mathrm{PS}-\mathrm{SO}_{3} \mathrm{H} @ m e s o s i l i c a s$ DSNs are stable and could be recycled.

After the first cycle, PS-SO $\mathrm{S}_{3} \mathrm{H} @$ mesosilicas DSNs have similar morphology as the fresh ones in acid-catalysed reactions, including esterification of fatty acid, Friedel-Crafts alkylation of toluene and CHP (cumene hydroperoxide) cleavage reactions (Supplementary Fig. 12). However, the morphology changes from double-shell HNs to HNs, and the BET surface area and pore volume decrease obviously after eighth cycle in the esterification reaction, probably due to the polymer swelling caused by the reactants and products during the catalytic process and the mesopore blockage by the swelled polymer.

In summary, a novel hybrid solid acid with DSN was fabricated on the basis of the self-assembly of $\mathrm{PS}_{-} \mathrm{SO}_{3} \mathrm{H}$ resin driven by $\mathrm{H}$-bond interactions among $\mathrm{SO}_{3} \mathrm{H}$ groups within the nanospace of silica HNs. Interestingly, it was found that the acid strength of PS-SO $\mathrm{S}_{3} \mathrm{H} @ m e s o s i l i c a s$ DSNs could be enhanced and decreased by restoring and destroying $\mathrm{H}$-bond interactions, respectively. PS$\mathrm{SO}_{3} \mathrm{H} @ m e s o s i l i c a s$ DSNs with enhanced acid strength and unique double-shell mesostructure show excellent catalytic activity and selectivity in a series of important acid-catalysed reactions. Our findings may offer a new approach to fabricate highly efficient solid acid catalysts for green chemical processes.

\footnotetext{
Methods

Chemicals and reagents. All materials were of analytical grade. Styrene was washed through an inhibitor remover column for removing the inhibitor and then distilled under vacuum before use. The other materials were used as received without any further purification. 1,2-Bis-(trimethoxysilyl)ethane (BTME), cetyltrimethylammonium bromide (CTAB) and triethylphosphine oxide (TEPO) were purchased from Sigma-Aldrich Company Ltd. (USA). Fluorocarbon surfactant, FC-4, was bought from YickVic Chemicals (Hong Kong). Tetraethoxysilane (TEOS) was obtained from Nanjing Shuguang Chemical Group (China). Other reagents were purchased from Shanghai Chemical Reagent, Inc. of the Chinese Medicine Group.
}

Synthesis of polystyrene template spheres. The PS template spheres were prepared by emulsion polymerization in a water system according to a modified method $^{49}$. Specifically, PVP $(0.55 \mathrm{~g})$ was dissolved into $50 \mathrm{ml}$ of deionized water and $6.5 \mathrm{ml}$ of styrene in a flask under vigorous stirring. Then, $0.15 \mathrm{~g}$ of $\mathrm{K}_{2} \mathrm{~S}_{2} \mathrm{O}_{8}$ dissolved in $20 \mathrm{ml}$ of water was added. Nitrogen was bubbled into the system for $1 \mathrm{~h}$ to remove the oxygen from the reactor. Then, reaction mixtures were sustained at $70^{\circ} \mathrm{C}$ for $24 \mathrm{~h}$ under argon atmosphere. After polymerization reaction, the solution was centrifuged and washed with water and ethanol for three times. The obtained white solid was dried under vacuum at $60^{\circ} \mathrm{C}$ overnight. For characterization procedures, see Supplementary Methods.

Synthesis of PS@mesosilicas YSNs. In the first step, the silica layer was coated on the PS template using the following procedure: a mixture of $\mathrm{H}_{2} \mathrm{O}(60 \mathrm{ml})$, ethanol $(20 \mathrm{ml})$, CTAB $(0.2 \mathrm{~g})$, PS template spheres $(0.2 \mathrm{~g})$ and $\mathrm{NH}_{3} \cdot \mathrm{H}_{2} \mathrm{O}(0.7 \mathrm{ml}$ $25 \mathrm{wt} \%)$ was stirred at $50^{\circ} \mathrm{C}$ for $0.5 \mathrm{~h}$. Then, TEOS $(0.5 \mathrm{~g})$ was added and the mixture was stirred for $2 \mathrm{~h}$, followed by the addition of an aqueous solution ( $3 \mathrm{ml})$ containing FC-4 (0.04 g), CTAB (0.08 g) and $\mathrm{NH}_{3} \cdot \mathrm{H}_{2} \mathrm{O}(0.20 \mathrm{ml}, 25 \mathrm{wt} \%)$. The mixture was stirred for $0.5 \mathrm{~h}$. The second step involves selective etching according to the following procedure: BTME $(0.50 \mathrm{ml})$ in ethanol solution $(2 \mathrm{ml})$ was added subsequently under vigorous stirring to the above synthesis medium. After stirring for $2 \mathrm{~min}$, the temperature was raised to $80^{\circ} \mathrm{C}$ and kept for $2 \mathrm{~h}$, and the white powder was collected by filtration and dried at room temperature. To remove the surfactant, the as-synthesized materials $(1 \mathrm{~g})$ were dispersed in $200 \mathrm{ml}$ of ethanol containing $1.5 \mathrm{~g}$ of concentrated $\mathrm{HCl}$ aqueous solution and the mixture was stirred at $70^{\circ} \mathrm{C}$ for $12 \mathrm{~h}$. After centrifugation and washing with ethanol, the desired material was obtained. At last, the obtained solid was dried at $60^{\circ} \mathrm{C}$ overnight. The resulting powder products were denoted as PS@mesosilicas YSNs.

Synthesis of PS-SO $\mathbf{S O}_{3} \mathbf{H} @$ mesosilicas DSNs. Solid acids with DSN were obtained in one-pot step. In a typical procedure, PS@mesosilicas YSNs (1.0 g) were degassed at $120^{\circ} \mathrm{C}$ under vacuum for $3 \mathrm{~h}$. Then anhydrous dichloromethane $(50 \mathrm{ml})$-containing chlorosulphonic acid $(10 \mathrm{ml})$ was slowly introduced at $0^{\circ} \mathrm{C}$. The mixture was stirred at $0^{\circ} \mathrm{C}$ for $12 \mathrm{~h}$ under argon atmosphere. The suspension was washed with copious amount of water until the filtrate was neutral. After centrifugation and washing with ethanol, the desired material was obtained. Finally, the solid was dried at $60^{\circ} \mathrm{C}$ overnight. The resulting powder products were denoted as PS-SO ${ }_{3} \mathrm{H} @ m e s o s i l i c a s$ DSNs.

Treatment of PS@mesosilicas DSNs in different organic solvents. To investigate the stability of PS@mesosilicas DSNs, PS@mesosilicas DSNs (0.1 g) were treated in different types of organic solvents $(10 \mathrm{ml}$; the organic solvent includes methanol, THF, ethanol, dioxane, water, pyridine, pentane and DMF) for $12 \mathrm{~h}$ under stirring at room temperature. After centrifugation and washing with ethanol, the powder products were dried at $60^{\circ} \mathrm{C}$ overnight.

General procedure for acid-catalysed reactions. Esterification of lauric acid with ethanol was carried out in a two-necked round flask equipped with a reflux condenser and a magnetic stirrer. The catalyst was pretreated at $120^{\circ} \mathrm{C}$ under vacuum for $3 \mathrm{~h}$. In a typical experiment, $10 \mathrm{mmol}$ of ethanol and $2 \mathrm{mmol}$ of lauric acid were added to the flask containing $0.05 \mathrm{~g}$ of PS@mesosilicas DSNs $(0.04 \mathrm{mmol}$ of acid sites). The mixture was stirred at $80^{\circ} \mathrm{C}$ for $6 \mathrm{~h}$. The reaction products were 
collected by a syringe at regular intervals and analysed using a precalibrated gas chromatograph (Agilent 7890) equipped with a flame ion detector (FID) and PEG capillary column $(30 \mathrm{~m} \times 0.25 \mathrm{~mm} \times 0.25 \mu \mathrm{m})$. Tetradecane was used as an internal standard.

Liquid-phase Friedel-Crafts alkylation of toluene by benzyl alcohol was carried out in a two-necked round-bottom flask coupled with a reflux condenser in a temperature-controlled oil bath. In a typical experiment, $0.05 \mathrm{~g}$ of PS@mesosilicas DSNs ( $0.04 \mathrm{mmol}$ of acid sites) catalyst was added to a reactant mixture of $0.25 \mathrm{~g}$ of benzyl alcohol in $10.0 \mathrm{ml}$ of toluene, with $0.05 \mathrm{~g}$ of tetradecane as an internal standard for the GC analysis. The reaction was refluxed under vigorous magnetic stirring at $80^{\circ} \mathrm{C}$ for $7 \mathrm{~h}$. The reaction mixture was monitored using gas chromatography (GC, Agilent-7890A) equipped with a FID and a HP-5 column $(30 \mathrm{~m} \times 0.32 \mathrm{~mm} \times 0.25 \mu \mathrm{m})$. GC-mass spectrometer $(\mathrm{GC}-\mathrm{MS})$ was also used to identify the reaction products.

The CHP cleavage reaction was carried out in a round-bottom flask coupled with a reflux condenser in a temperature-controlled water bath. In a typical experiment, $0.01 \mathrm{~g}$ of PS@mesosilicas DSNs $\left(8.7 \times 10^{-3} \mathrm{mmol}\right.$ of acid sites) catalyst was added to $1.0 \mathrm{~g}$ of CHP with $0.1 \mathrm{~g}$ of tetradecane as an internal standard for GC analysis. The reaction mixture was refluxed under vigorous magnetic stirring at $50{ }^{\circ} \mathrm{C}$ for $1 \mathrm{~h}$. The concentration of CHP and phenol was monitored using gas chromatography (GC, Agilent-7890A) equipped with a FID and a HP-5 column $(30 \mathrm{~m} \times 0.32 \mathrm{~mm} \times 0.25 \mu \mathrm{m})$.

The reusability of PS-SO $\mathrm{SO}_{3} \mathrm{H} @$ mesosilicas DSNs was tested using esterification of lauric acid with ethanol as the model reaction. In a typical experiment, $10 \mathrm{mmol}$ of ethanol and $2 \mathrm{mmol}$ of lauric acid were added to the flask containing $0.10 \mathrm{~g}$ of catalyst. The mixture was stirred at $80^{\circ} \mathrm{C}$ for $6 \mathrm{~h}$. After the completion of one cycle, the catalyst was filtered from the reaction system, thoroughly washed with ethanol, dried under vacuum at $60^{\circ} \mathrm{C}$ overnight and then used in the next cycle.

\section{References}

1. Corma, A. Inorganic solid acids and their use in acid-catalyzed hydrocarbon reactions. Chem. Rev. 95, 559-614 (1995).

2. Corma, A. Solid acid catalysts. Curr. Opin. Solid State Mater. Sci. 2, 63-75 (1997).

3. Corma, A. \& Garcia, H. Lewis acids: from conventional homogeneous to green homogeneous and heterogeneous catalysis. Chem. Rev. 103, 4307-4365 (2003).

4. Clark, J. H. Solid acids for green chemistry. Acc. Chem. Res. 35, 791-797 (2002).

5. Climent, M. J., Corma, A. \& Iborra, S. Heterogeneous catalysts for the one-pot synthesis of chemicals and fine chemicals. Chem. Rev. 111, 1072-1133 (2011).

6. Pourjavadi, A., Hosseini, S. H., Doulabi, M., Fakoorpoor, S. M. \& Seidi, F. Multi-layer functionalized poly(ionic liquid) coated magnetic nanoparticles: highly recoverable and magnetically separable bronsted acid catalyst. ACS Catal. 2, 1259-1266 (2012)

7. Liu, F. et al. Transesterification catalyzed by ionic liquids on superhydrophobic mesoporous polymers: heterogeneous catalysts that are faster than homogeneous catalysts. J. Am. Chem. Soc. 134, 16948-16950 (2012).

8. Liu, F., Kong, W., Qi, C., Zhu, L. \& Xiao, F. S. Design and synthesis of mesoporous polymer-based solid acid catalysts with excellent hydrophobicity and extraordinary catalytic activity. ACS Catal. 2, 565-572 (2012).

9. Liu, F. et al. Efficient and stable solid acid catalysts synthesized from sulfonation of swelling mesoporous polydivinylbenzenes. J. Catal. 271, 52-58 (2010).

10. Siril, P. F., Cross, H. E. \& Brown, D. R. New polystyrene sulfonic acid resin catalysts with enhanced acidic and catalytic properties. J. Mol. Catal. A Chem. 279, 63-68 (2008)

11. Harmer, M. A. \& Sun, Q. Solid acid catalysis using ion-exchange resins. Appl. Catal. A-Gen. 221, 45-62 (2001).

12. Hart, M., Fuller, G., Brown, D. R., Dale, J. A. \& Plant, S. Sulfonated poly(styrene-co-divinyl -benzene) ion-exchange resins: acidities and catalytic activities in aqueous reactions. J. Mol. Catal. A Chem. 182, 439-445 (2002).

13. Barbaro, P. \& Liguori, F. Ion exchange resins: catalyst recovery and recycle. Chem. Rev. 109, 515-529 (2009).

14. Choi, M. et al. Controlled polymerization in mesoporous silica toward the design of organic-inorganic composite nanoporous materials. J. Am. Chem. Soc. 127, 1924-1932 (2005).

15. Martín, A. et al. Acid hybrid catalysts from poly(styrenesulfonic acid) grafted onto ultra-large-pore SBA-15 silica using atom transfer radical polymerization. J. Mater. Chem. 20, 8026-8035 (2010).

16. Long, W. \& Jones, C. W. Hybrid sulfonic acid catalysts based on silicasupported poly(styrene sulfonic acid) brush materials and their application in ester hydrolysis. ACS Catal. 1, 674-681 (2011).

17. Li, C., Yang, J., Wang, P., Liu, J. \& Yang, Q. An efficient solid acid catalyst: poly-p-styrenesulfonic acid supported on SBA-15 via surface-initiated ATRP. Microporous Mesoporous Mater. 123, 228-233 (2009).

18. Melero, J. A., Stucky, G. D., van Grieken, R. \& Morales, G. Direct syntheses of ordered SBA-15 mesoporous materials containing arenesulfonic acid groups. J. Mater. Chem. 12, 1664-1670 (2002).
19. Siegel, R. et al. Understanding the high catalytic activity of propylsulfonic acid-functionalized periodic mesoporous benzenesilicas by high-resolution ${ }^{1} \mathrm{H}$ solid-state NMR spectroscopy. J. Mater. Chem. 22, $7412-7419$ (2012).

20. Mbaraka, I. K. \& Shanks, B. H. Acid strength variation due to spatial location of organosulfonic acid groups on mesoporous silica. J. Catal. 244, 78-85 (2006)

21. Brandle, M. \& Sauer, J. Acidity differences between inorganic solids induced by their framework structure- a combined quantum mechanics molecular mechanics ab initio study on zeolites. J. Am. Chem. Soc. 120, 1556-1570 (1998).

22. Dacquin, J. P. et al. Interdependent lateral interactions, hydrophobicity and acid strength and their influence on the catalytic activity of nanoporous sulfonic acid silicas. Green Chem. 12, 1383-1391 (2010).

23. Liu, F. et al. High-temperature synthesis of magnetically active and $\mathrm{SO}_{3} \mathrm{H}$-functionalized ordered mesoporous carbon with good catalytic performance. Catal. Today 186, 115-120 (2012).

24. Kitano, M. et al. Protonated titanate nanotubes with lewis and brønsted acidity: relationship between nanotube structure and catalytic activity. Chem. Mater. 25, 385-393 (2013).

25. Selvaraj, M., Min, B. R., Shul, Y. G. \& Lee, T. G. Comparison of mesoporous solid acid catalysts in the production of DABCO by cyclization of ethanolamine I. Synthesis and characterization of mesoporous solid acid catalysts. Microporous and Mesoporous Mater. 74, 143-155 (2004).

26. Kalita, P., Gupta, N. M. \& Kumar, R. Synergistic role of acid sites in the Ce-enhanced activity of mesoporous Ce-Al-MCM-41 catalysts in alkylation reactions: FTIR and TPD-ammonia studies. J. Catal. 245, 338-347 (2007).

27. Harmer, M. A., Farneth, W. E. \& Sun, Q. High surface area nafion resin/silica nanocomposites: a new class of solid acid catalyst. J. Am. Chem. Soc. 118, 7708-7715 (1996).

28. Sijbesma, R. P. et al. Reversible polymers formed from self-complementary monomers using quadruple H-bond. Science 278, 1601-1604 (1997).

29. Stuart, M. A. C. et al. Emerging applications of stimuli-responsive polymer materials. Nat. Mater. 9, 101-113 (2010).

30. Fu, Q. et al. Reversible control of free energy and topography of nanostructured surfaces. J. Am. Chem. Soc. 126, 8904-8905 (2004).

31. Whitesides, G. M., Mathias, J. P. \& Seto, C. T. Molecular self-assembly and nanochemistry-a chemical strategy for the synthesis of nanostructures. Science 254, 1312-1319 (1991).

32. Prins, L. J., Reinhoudt, D. N. \& Timmerman, P. Noncovalent synthesis using H-bond. Angew. Chem. Int. Ed. 40, 2382-2426 (2001).

33. Chen, D. Y. \& Jiang, M. Strategies for constructing polymeric micelles and hollow spheres in solution via specific intermolecular interactions. Acc. Chem. Res. 38, 494-502 (2005).

34. Yang, Y., Liu, J., Li, X., Liu, X. \& Yang, Q. Organosilane-assisted transformation from core-shell to yolk-shell nanocomposites. Chem. Mater. 23, 3676-3684 (2011).

35. Yang, Y. et al. A yolk-shell nanoreactor with a basic core and an acidic shell for cascade reactions. Angew. Chem. Int. Ed. 51, 9164-9168 (2012).

36. Liu, J. et al. Yolk-shell hybrid materials with a periodic mesoporous organosilica shell: ideal nanoreactors for selective alcohol oxidation. Adv. Funct. Mater. 22, 591-599 (2012).

37. Haw, J. F. \& Xu, T. NMR studies of solid acidity. Adv. Catal. 42, 115-180 (1998).

38. Grunberg, B. et al. H-bond of water confined in mesoporous silica MCM-41 and SBA-15 studied by ${ }^{1} \mathrm{H}$ solid-state NMR. Chemistry 10, 5689-5696 (2004).

39. Haw, J. F. Zeolite acid strength and reaction mechanisms in catalysts. Phys. Chem. Chem. Phys. 4, 5431-5441 (2002).

40. Hamoudi, S. \& Kaliaguine, S. Periodic mesoporous organosilica from micellar oligomer template solution. Chem. Commun. 18, 2118-2119 (2002).

41. Farcasiu, D., Ghenciu, A., Marino, G. \& Rose, K. D. Strength of solid acids and acids in solution. Enhancement of acidity of centers on solid surfaces by anion stabilizing solvents and its consequence for catalysis. J. Am. Chem. Soc. 119, 11826-11831 (1997).

42. Zheng, A. et al. ${ }^{31} \mathrm{P}$ chemical shift of adsorbed trialkylphosphine oxides for acidity characterization of solid acids catalysts. J. Phys. Chem. A 112, 7349-7356 (2008).

43. Zheng, A., Huang, S.-J., Liu, S.-B. \& Deng, F. Acid properties of solid acid catalysts characterized by solid-state ${ }^{31} \mathrm{P}$ NMR of adsorbed phosphorous probe molecules. Phys. Chem. Chem. Phys. 13, 14889-14901 (2011).

44. Lunsford, J. H., Rothwell, W. P. \& Shen, W. Acid sites in zeolite-Y-a solid-state NMR and infrared study using trimethylphosphine as a probe molecule. J. Am. Chem. Soc. 107, 1540-1547 (1985).

45. Siril, P. F., Davison, A. D., Randhawa, J. K. \& Brown, D. R. Acid strengths and catalytic activities of sulfonic acid on polymeric and silica supports. J. Mol. Catal. A Chem. 267, 72-78 (2007). 
46. Chiu, J. J., Pine, D. J., Bishop, S. T. \& Chmelka, B. F. Friedel-Crafts alkylation properties of aluminosilica SBA-15 meso/macroporous monoliths and mesoporous powders. J. Catal. 221, 400-412 (2004).

47. Dou, J. \& Zeng, H. C. Targeted synthesis of silicomolybdic acid (Keggin acid) inside mesoporous silica hollow spheres for Friedel-Crafts alkylation. J. Am. Chem. Soc. 134, 16235-16246 (2012).

48. Busca, G. Acid catalysts in industrial hydrocarbon chemistry. Chem. Rev. 107, 5366-5410 (2007).

49. Deng, Z., Chen, M., Zhou, S., You, B. \& Wu, L. A novel method for the fabrication of monodisperse hollow silica spheres. Langmuir 22, 6403-6407 (2006).

\section{Acknowledgements}

This work was financially supported by the National Natural Science Foundation of China $(21325313,21232008$ and 21103180).

\section{Author contributions}

Q.Y. conceived and supervised the project; X.Z. did all the experiments and wrote the manuscript; Y.Z. discussed the data; S.X. and Y.W. did the NMR characterization of the materials; Y.Y. and J.L. discussed the data; X.Z. and Y.Z. contributed equally to this study.

\section{Additional information}

Supplementary Information accompanies this paper at http://www.nature.com/ naturecommunications

Competing financial interests: The authors declare no competing financial interests.

Reprints and permission information is available online at http://npg.nature.com/ reprintsandpermissions/

How to cite this article: Zhang, X. et al. Polystyrene sulphonic acid resins with enhanced acid strength via macromolecular self-assembly within confined nanospace. Nat. Commun. 5:3170 doi: 10.1038/ncomms4170 (2014). 